$\mathbb{T}$ periodica polytechnica

Mechanical Engineering

$53 / 2$ (2009) $9 3 \longdiv { 9 9 }$

doi: 10.3311/pp.me.2009-2.07

web: http://www.pp.bme.hu/me

(c) Periodica Polytechnica 2009

RESEARCH ARTICLE

\section{Global, depth sensing and dynamic hardness of metal matrix syntactic foams}

\author{
Imre Norbert Orbulov ${ }^{1}$ / Árpád Németh
}

Received 2010-08-12

\begin{abstract}
This paper deals with the hardness testing of metal matrix syntactic foams (MMSFs). The hardness of the foams was characterized by three different hardness testing methods: global (or Brinell-like) hardness, depth sensing hardness and dynamic hardness were measured. Although the matrices had significant global hardness difference; the global hardness of the foams was almost the same regardless of the type of the matrix. Therefore, the global hardness of the MMSFs is structural property. The depth sensing hardness tests showed great sensitivity to the deformation capability of the matrices and to the presence of a possible change reaction between the reinforcement and the matrices. The dynamic hardness values of the MMSFs were higher than the dynamic hardness of the matrices. The original hardness difference between matrices decreased by microballoon incorporation.
\end{abstract}

\section{Keywords}

metal matrix composites · syntactic foams · ceramic hollow microspheres $\cdot$ ceramic microballoons $\cdot$ hardness test

\section{Acknowledgement}

Thanks to prof. J. T. Blücher for his kind support and to Gy. Vörös for his help in depth sensing hardness tests. This paper was supported by the János Bolyai Research Scholarship of the Hungarian Academy of Sciences. The investigations were supported by The Hungarian Research Fund, NKTH-OTKA PD 83687. This work is connected to the scientific program of the "Development of quality-oriented and harmonized $R+D+I$ strategy and functional model at BME" project. This project is supported by the New Hungary Development Plan (Project ID: TÁMOP-4.2.1/B-09/1/KMR-2010-0002). Thanks to R. Tóth and C. H. Erbslöh Hungaria Ltd. for providing E-spheres.

\section{Imre Norbert Orbulov ${ }^{1}$}

Department of Materials Science and Engineering, BME, H-1111 Budapest, Bertalan Lajos utca 7, Hungary

e-mail: orbulov@gmail.com

\section{Árpád Németh}

Department of Materials Science and Engineering, BME, H-1111 Budapest, Bertalan Lajos utca 7, Hungary

\section{Introduction}

The 'conventional' metallic foams, which contain metallic and gas phase only, have widespread literature. However, there are still existing problems for example in accordance with the foaming process of the foams [1,2]. A special class of foams, the so called syntactic foam, was developed in the late sixties. The first paper on syntactic foams was published in 1969 [3], these were polymer matrix syntactic foams and they have been investigated by many authors [4]-[7]. Later, the metal matrix syntactic foams (MMSFs) were developed at about the 1980s. They are closed cell foams, but they can be also classified as particle reinforced composite. In these composites the porosity is ensured by the incorporation of hollow ceramic microspheres. The microspheres contain various oxides, typically $\mathrm{SiO}_{2}, \mathrm{Al}_{2} \mathrm{O}_{3}, \mathrm{MgO}, \mathrm{Fe}_{2} \mathrm{O}_{3}$ and $\mathrm{K}_{2} \mathrm{O}$. The most common matrix material is aluminium alloy, but there were some experiments with $\mathrm{ZnAl}$ alloy also [8]. In the future a better choice would be magnesium alloys because of their lower density.

MMSFs can be produced by blending method or by pressure infiltration. The blending method is easier, but only lower microsphere volume fraction can be reached [9]-[11]. When higher volume fraction is necessary, pressure infiltration technique is applied [12]-[17]. For successful pressure infiltration a threshold pressure must be ensured, which can be estimated by theoretical and experimental methods. Bárczy and Kaptay developed a theoretical method considering wetting angle, surface tension and based on the equilibrium of gravitational, capillary and outer forces [18]. It is somewhat simpler to define a hydraulic radius, depending on the shape and volume fraction of the hollow microspheres and apply the Young-Laplace equation to evaluate threshold pressure [19]. In a similar method the effective distance between the hollow microspheres is determined and again the Young-Laplace equation used to calculate the threshold pressure [12].

Due to their low density, MMSFs have perspective applications in covers, castings, furniture and engine blocks in the automotive and electromechanical industry sectors. Other advantages of the MMSFs are high specific compression strength and

\footnotetext{
${ }^{1}$ Corresponding author
} 
thermal stability. Therefore, they are also used as energy absorbers, sound absorbers or as material of hulls in submarine applications and aeronautics [20]. The compressive characteristics of syntactic foams are extremely important, because compression is the main load type in the case of their potential applications listed above. Therefore the compression behaviours have been widely studied [21]-[25].

Palmer et al. applied different aluminium matrices and investigated their mechanical properties by upsetting, tensile and bending tests [25]. Beside these mechanical properties, the hardness of MMSFs is very important in the aspect of different applications. The hardness, especially the global hardness (measured on a relatively large area), is in strong connection with the wear, both in dry and wet conditions [10], [26]-[27]. The global hardness can be determined by the indentation of a hard steel ball, like in the conventional Brinell-method [9]. The hardness has also determining effect on the resistance against indentation, which is important because it has effect on the energy absorbing ability of the foams. However, this property can not be confidently measured by global hardness test because of the too shallow indentation. Therefore, a special testing method, the so called depth sensing hardness test should be applied [28]-[31]. This method records the load-indentation curves from which the elastic and plastic parts of the absorbed energy can be calculated. Moreover, the depth sensing hardness measurements are sensitive to the microstructural differences (see section 4). The above mentioned quasi-static tests are not applicable when the dynamic properties have to be determined such in the case of collisions. The dynamic properties can be measured by shooting a defined mass to the surface of the specimen, while measuring its velocity before $\left(\mathrm{v}_{b}\right)$ and $\operatorname{after}\left(\mathrm{v}_{a}\right)$ the impact. The ratio of the velocities multiplied by 1000 is the dynamic hardness $\left(\mathrm{HD}=1000 \cdot \mathrm{v}_{a} / \mathrm{v}_{b} \mathrm{HL}\right)$. This number characterizes the dynamic properties of the MMSFs.

Beside the comparable hardness values it is an important possibility to find connections between different hardness values and other mechanical or physical properties. The aim of this paper is to present and explain the different hardness values and their connection to other mechanical properties.

\section{Investigated materials}

Six types of MMSFs were produced by pressure infiltration in the Metal Matrix Composite Laboratory of Budapest University of Technology and Economics. Overall twelve blocks were made, two blocks from each type. The matrix materials were AlSi12 or A199.5 aluminium alloys and three types of ceramic hollow microspheres (SL150, SLG and SL300) were applied as reinforcement. All of them were provided by Envirospheres Pty. Ltd. under the trade name E-spheres. Their main geometrical parameters and chemical composition (according to our measurements [32]) are listed in Table 1 (in the third column the so called specific surface means the ratio of surface area and volume). Some of the microspheres are originally broken; these were eliminated by a buoyant method.

The first step in the production was to pour the reinforcement into a can (moulding form, its inner volume was $35 \times 55 \times 170$ $\mathrm{mm}$ ). The microspheres were compacted by gently tapping. By this way $\sim 64$ vol\% of microspheres can be incorporated. After that, an insulator layer $\left(\mathrm{Al}_{2} \mathrm{O}_{3}\right)$ was placed on the top of the reinforcement. The function of this layer is to separate the reinforcement and the matrix in the first period of the infiltration (heating). Then a block of the matrix material was placed on the top of the insulator. At the same time two thermocouples were placed into the can to register the temperature of the reinforcement and the matrix block. Later the whole production process was controlled by these temperature data. After this, the prepared moulding can was placed in a special infiltration chamber (see Fig. 11. Then the chamber was closed and evacuated. Beside this the heating was started and the matrix block was melted. The molten metal formed a liquid cork in the can and separated its volume into two parts (the reinforcement in the can and the remaining part of the chamber, outside the can). When the matrix reached the infiltration temperature $\left(600^{\circ} \mathrm{C}\right.$ and $710^{\circ} \mathrm{C}$ in the case of $\mathrm{AlSi} 12$ and $\mathrm{A} 199.5$ matrix respectively), $\mathrm{Ar}$ gas was let to flow into the chamber with a previously sat infiltrating pressure $(0.4 \mathrm{MPa} \approx 4$ bar $)$. The pressure was maintained for $30 \mathrm{~s}$. When the gas was let into the chamber a pressure difference between the volume part of the reinforcement and the other part of the chamber was built up. This pressure difference forced the melted matrix material between the microspheres. After the infiltration the can was removed from the chamber and cooled down. The blocks were investigated in as-fabricated state and they were named after their constituents. For example AlSi12SLG means that, the specimen has AlSi12 aluminium alloy matrix and contains $\sim 64$ vol\% SLG type hollow microspheres.

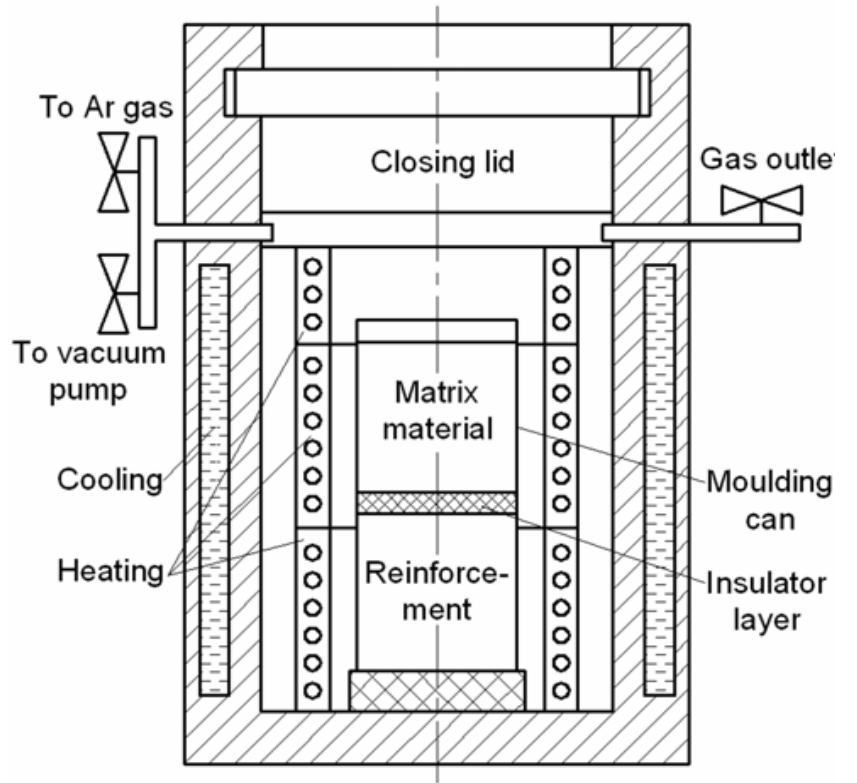

Fig. 1. Schematic drawing of the infiltration chamber

Before the mechanical tests (such like compressive, tensile or hardness tests) it is necessary to qualify the produced blocks in 
Tab. 1. Geometrical dimensions and phase composition (wt \%) of the hollow ceramic spheres [32]

\begin{tabular}{|c|c|c|c|c|c|c|c|}
\hline Type & $\begin{array}{l}\text { Average } \\
\text { diameter } \\
(\mu \mathrm{m})\end{array}$ & $\begin{array}{l}\text { Specific surface } \\
\left(\mu \mathrm{m}^{-1}\right)\end{array}$ & $\mathrm{Al}_{2} \mathrm{O}_{3}$ & $\begin{array}{l}\text { Amorphous } \\
\mathrm{SiO}_{2}\end{array}$ & Mullite & Quartz & Other \\
\hline SL150 & 100 & 0.060 & & & & & \\
\hline SLG & 130 & 0.046 & $30-35 \%$ & $45-50 \%$ & $19 \%$ & $1 \%$ & Bal. \\
\hline SL300 & 150 & 0.040 & & & & & \\
\hline
\end{tabular}

the aspect of porosity. This is the most important parameter of the foams, because it has determinant effect on every mechanical property. The total porosity can be divided into two groups. The first is the so called "planned porosity", it is originated from the hollow microspheres. The second is the "unwanted porosity", which can be originated from the insufficient infiltration and usually situated where three or more microspheres are in close connection. Therefore, optical microscopic pictures were taken (Fig. 2a and b) at several places of the blocks in order to qualify them. Because of the same reason, porosities were calculated by image analysis method. Their averages are indicated in Table 2. Almost perfect infiltration can be observed in the pictures, only a small amount of unwanted porosity can be found between microspheres, which are in close connection. The unwanted porosity remained always below $2.5 \%$. The negative values of unwanted porosity mean that, the infiltration pressure broke some microspheres and they were infiltrated. The negative unwanted porosity never reached $7.5 \%$. The small values of unwanted porosity (either positive or negative) indicate near perfect infiltration and little effect on the mechanical porosities.

Tab. 2. The average porosity values of the produced MMSF blocks

\begin{tabular}{llll}
\hline Type & Total (\%) & Planned (\%) & Unwanted (\%) \\
\hline Al99.5-SL150 & 44.67 & 50.86 & -6.18 \\
Al99.5-SLG & 43.66 & 49.46 & -5.80 \\
Al99.5-SL300 & 41.04 & 48.22 & -7.19 \\
AISi12-SL150 & 51.99 & 50.86 & 1.13 \\
AISi12-SLG & 51.50 & 49.46 & 2.03 \\
AISi12-SL300 & 50.12 & 48.22 & 1.89 \\
\hline
\end{tabular}

\section{Experimental methods}

The main aim of this paper is to determine the global, the depth sensing and the dynamic hardness of the produced MMSF blocks.

The global hardness was measured by Brinell-method. The measurements were performed on a VPM HPO 13/6062 type hardness tester at room temperature $\left(23^{\circ} \mathrm{C}\right)$. The indenter was an $\varnothing 10 \mathrm{~mm}$ hard steel ball. This is the largest in the Brinellsystem; therefore it made the largest indentation and measures the global hardness. The loading force was $1839 \mathrm{~N}$ (187.5 kp) and $2452 \mathrm{~N}$ (250 kp) in the case of Al99.5 and AlSi12 MMSF blocks respectively. The loading force was chosen according to the recommendation of the relating standard [33]. The loading was always maintained for $10 \mathrm{~s}$. The diameters of the indentation were measured and the global hardness was determined according to the Brinell-method. Ten measurements were done on every block, the results (HB) were averaged and the scatters $\left(\mathrm{s}_{H B}\right)$ were calculated.

The depth sensing hardness tests (not standardized, [28]-[31]) were done by a MTS 810 type universal testing machine. The indenter was an $\varnothing 2.5 \mathrm{~mm}$ mandrel with hemisphere ending. The measurements were continued until $1600 \mathrm{~N}$ reaction force was reached. The crosshead velocity was $0.02 \mathrm{mms}^{-1}$, so the tests were quasi static. The loading force was recorded in the function of indentation depth. The tests were carried out at room temperature and ten measurements were done on every block. The slope of the loading $(\mathrm{SL})$, the total $\left(\mathrm{W}_{t}\right)$, the elastic $\left(\mathrm{W}_{e}\right)$ and the plastic $\left(\mathrm{W}_{p}\right)$ absorbed energy were determined and averaged. Their scatters were also calculated $\left(\mathrm{s}_{S L}, \mathrm{~s}_{W t}, \mathrm{~s}_{W e}, \mathrm{~s}_{W p}\right)$.

The dynamic hardness tests were measured by an Equotip type device, which is satisfying the ASTM 956-96 standard. The device shoots an indenter with hemisphere ending to the surface of the investigated block and measures its velocity before $\left(\mathrm{v}_{b}\right)$ and after $\left(\mathrm{v}_{a}\right)$ the impact. The ratio of the velocities multiplied by 1000 is the dynamic hardness $\left(\mathrm{HD}=1000 \cdot \mathrm{v}_{a} / \mathrm{v}_{b}\right.$ $\mathrm{HL}$ ). This number characterizes the dynamic properties of the MMSFs. The mass of the indenter was $5 \mathrm{~g}$. The tests were done at room temperature and overall ten measurements were performed on every block. The dynamic hardness (HD) and its scatter $\left(\mathrm{s}_{H D}\right)$ were determined.

\section{Results and discussion}

The results of the global hardness tests are presented in Fig. 3 The scatter of the measurements was in the tolerable range, never exceeded 2.6 HBS. In the case of A199.5 matrix MMSFs the hardness increased compared to the pure matrix material. The matrix started to deform plastically before the hollow microspheres started to brake. Therefore the MMSFs were harder than the pure matrix. On the other hand in the case of AlSi12 matrix the MMSFs were softer than the pure matrix materials. The matrix was harder and the microspheres started to break due to elastic deformation. The plastic deformation of the matrix only starts after the break of the microspheres.

The highest hardness values were ensured by SL150 type microspheres. The smallest microspheres ensure higher relative ceramic content in the composite, which results hardness improvement. Besides this they have the smallest average diameter 

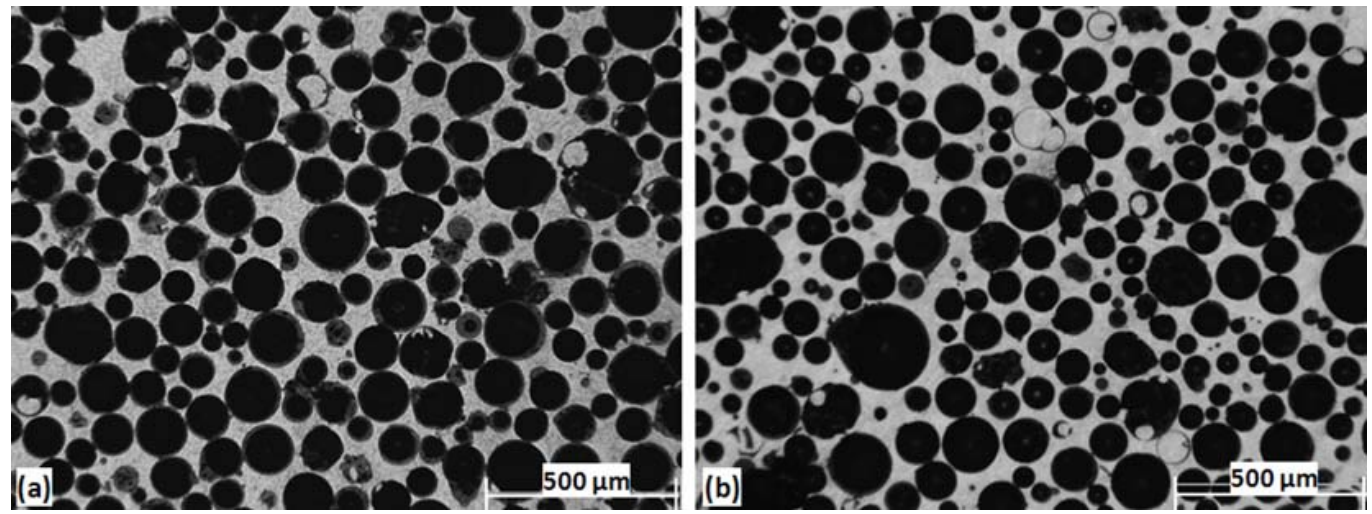

Fig. 2. Micrographs of A199.5-SLG (a) and AlSi12-SLG (b) type MMSFs

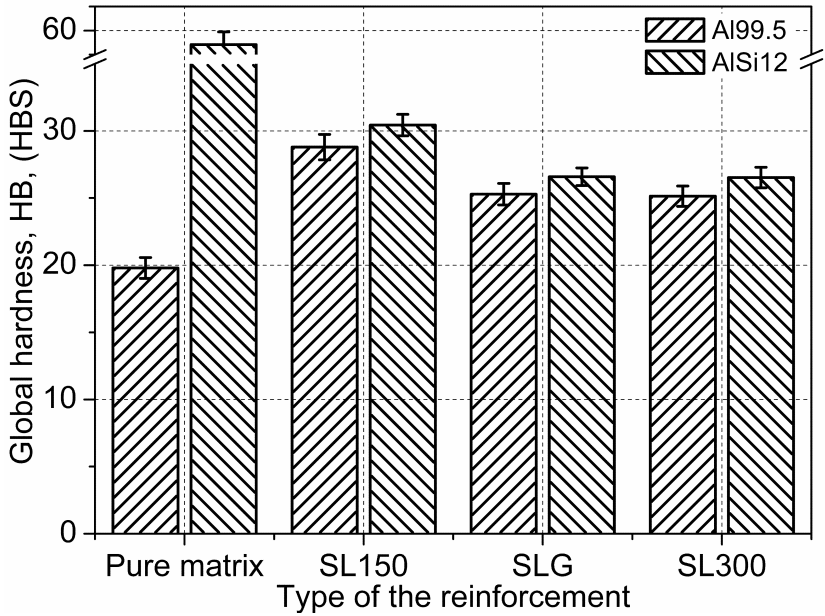

Fig. 3. The results of the global hardness tests

and therefore the largest specific surface. The large specific area resulted at lower stress in the microspheres at a given load level, therefore the microspheres began to break later. As the diameter increased (and the specific surface decreased) the stress at a given load level increased in the microspheres and they started to break earlier; the MMSFs became softer. It is also obvious from the diagram that, the pure matrix materials originally had $\sim 40$ HBS difference in their global hardness (the AlSi12 alloy is harder because of its Si content). This difference became negligible in the case of MMSFs. The composites with AlSi12 matrix were always a little harder, but they were very close to MMSFs with A199.5. Therefore the global hardness is originated from the structure, it is a structural property. The indentations made by the global hardness tests were also investigated. The indentations were cut out from the blocks and the specimens were grinded to the half. The sections were polished and micrographs were taken (see Fig. 4). The imprints were $\sim 0.2 \mathrm{~mm}$ deep. The microspheres were broken under the imprints within the same depth. The microspheres remained unharmed in the neighbourhood of the imprints, the damage extended only in the direction of the loading. This proves that, the MMSFs have good damage localizing ability.

After the global hardness tests depth sensing measurements were done. A typical recorded diagram is shown in Fig. 5. The waves are in connection with the breakage of microsphere sets. The elastic and plastic part of the absorbed energy was marked in the diagram.

The absorbed energies were calculated by numerical integration of the relevant parts of the recorded diagrams. The slopes of the loadings were determined through line fitting. The calculated energies with their scatter were plotted in Fig. 6 and Fig. 7 . The absorbed elastic energy was always low in the case of both matrices. The main part of the energy was absorbed plastically. The MMSFs with AlSi12 matrix (Fig. 6) absorbed $~ 2.5$ times more energy than the pure matrix. The type of the microspheres had negligible effect on the absorbed energy. The same trend was expected in the case of A199.5 matrix (Fig. 7).

However, in that case the pure matrix absorbed more energy (about the same as the MMSFs), but the SL150 and SLG type microspheres performed under the expected level. This was the consequence of an exchange reaction between the microspheres and the matrix material: $4 \mathrm{Al}_{(l i q)}+3 \mathrm{SiO}_{2(\text { sol })} \rightarrow 2 \mathrm{Al}_{2} \mathrm{O}_{3(\text { sol })}+3 \mathrm{Si}_{(\text {sol })}$ (detailed in our previous paper [32]). The reaction degraded the wall of the microspheres, their mechanical strength decreased and due to this their energy absorbing capability also decreased. If the exchange reaction did not take place, the absorbed energy would have been the same as in the case of pure A199.5 or in the case of SL300 reinforced MMSF. The decrement can be easily detected by depth sensing hardness tests, so this is a rapid and easy way to decide if any change reaction took place. Because of this, for qualitative information, it is not necessary to perform any expensive XRD or EDS tests. Furthermore the slope of the loading was in close connection with the absorbed energy. A linear connection can be assumed, as plotted in Fig. 8

The slope of the fitted line $(\mathrm{m})$, the intersection with the energy axis (y) and the correlation (R) are also presented in the graph. From this diagram the absorbed energy can be easily estimated from the slope of the loading (from Fig. 5) without further calculations. After the measurements the indentation were investigated in the same way as it is described earlier. Crosssections were cut out and polished to the half of the indentation (Fig.9). 

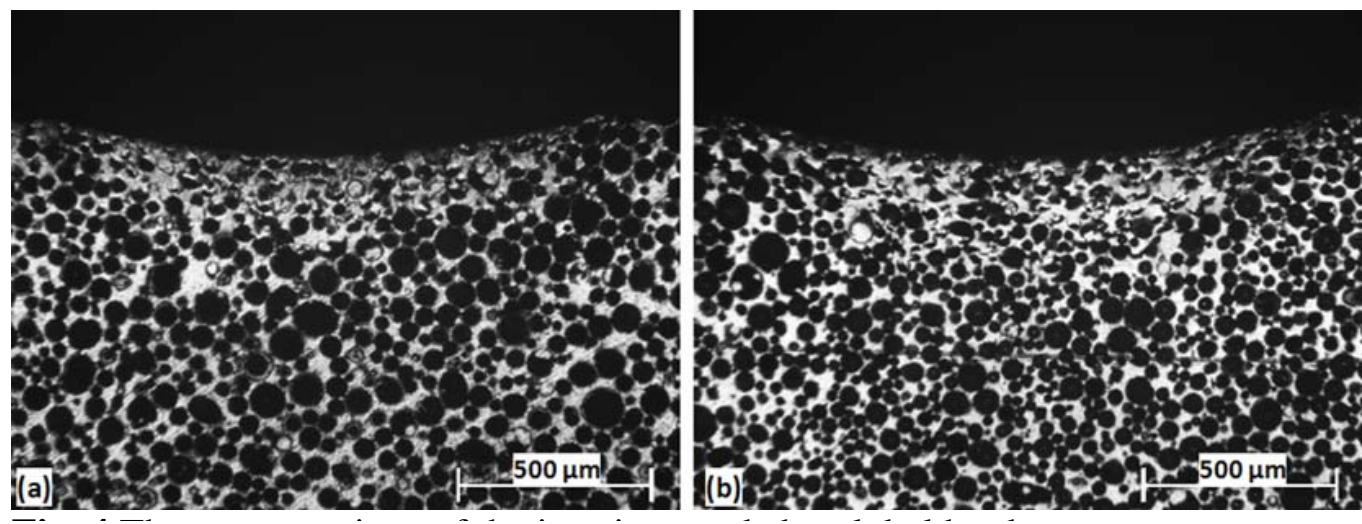

Fig. 4. The cross-sections of the imprints made by global hardness tests

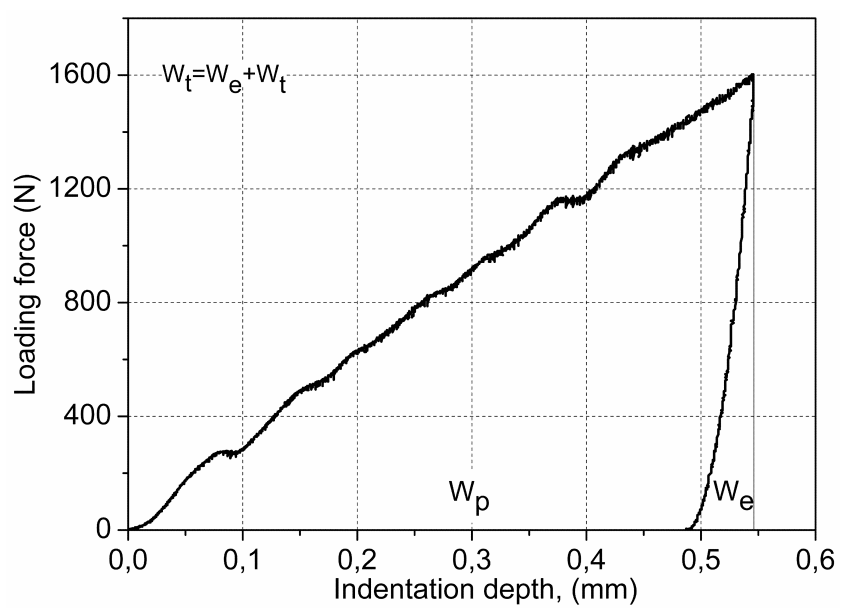

Fig. 5. Typical diagram of the depth sensing measurement

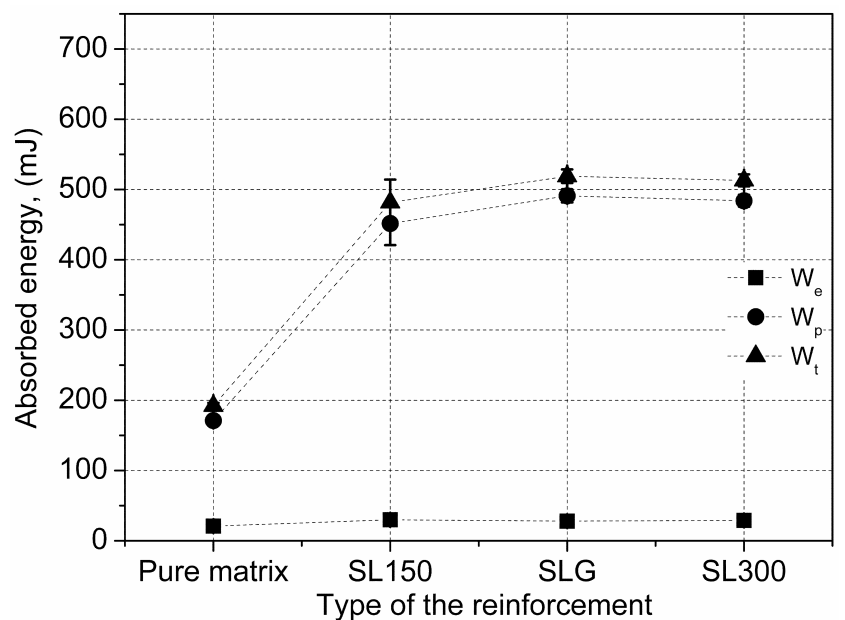

Fig. 6. The absorbed energies of the MMSFs with AlSi12 matrix $\left(\mathrm{W}_{t}=\right.$ total absorbed energy, $\mathrm{W}_{e}=$ elastic energy, $\mathrm{W}_{p}=$ plastic energy)

The indentations were deeper than in the case of global hardness tests, because the load was approximately the same and the diameter of the mandrel was smaller. The depths were $\sim 0.4$ $\mathrm{mm}$, the affected zone below the indentation were $\sim 0.5 \mathrm{~mm}$. Again, the microspheres were broken only under the imprint, the surrounding microspheres remained unharmed. This is again the evidence of the good damage localizing capability of the MMSFs.

The dynamic hardness values with their scatter are plotted

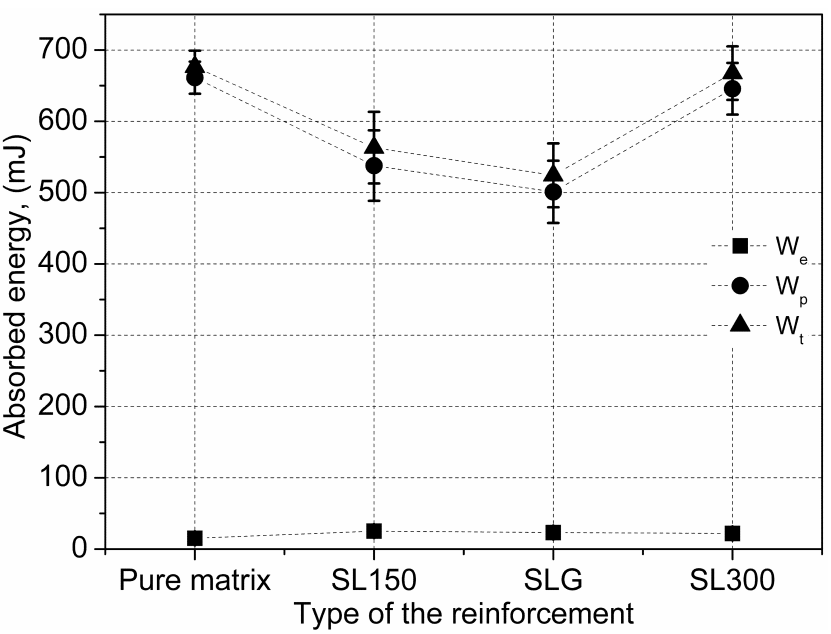

Fig. 7. The absorbed energies of the MMSFs with A199.5 matrix $\left(\mathrm{W}_{t}=\right.$ total absorbed energy, $\mathrm{W}_{e}=$ elastic energy, $\mathrm{W}_{p}=$ plastic energy)

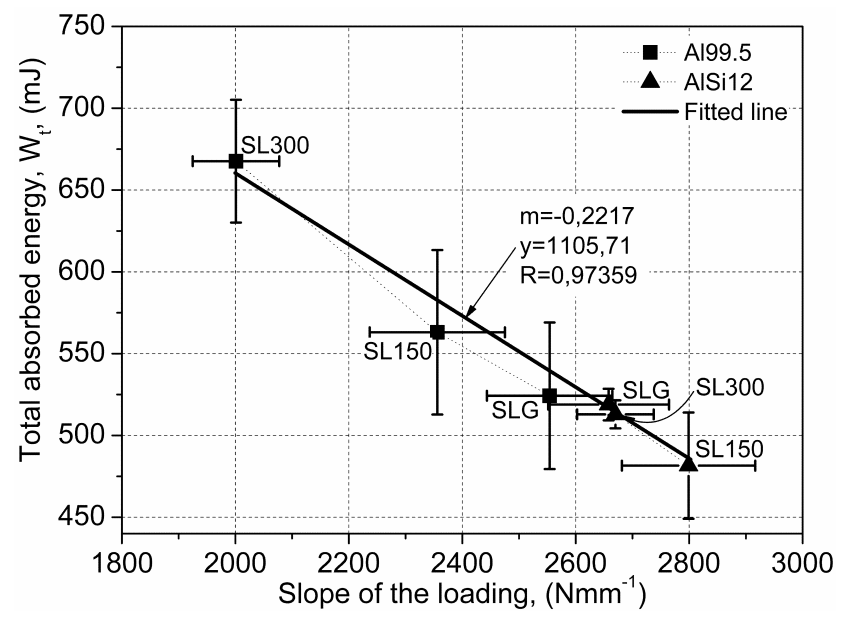

Fig. 8. The connection between the absorbed energy and the slope of the loading

in Fig. 10 The dynamic hardness of the MMSFs was always higher, than the matrixes', because of the high stiffness of the ceramic microspheres.

The original, $\sim 30 \%$ dynamic hardness difference between the pure matrix materials decreased to $\sim 15 \%$ in the case of MMSFs, so the matrix materials have low effect on the dynamic hardness. Therefore the dynamic hardness increment of the 

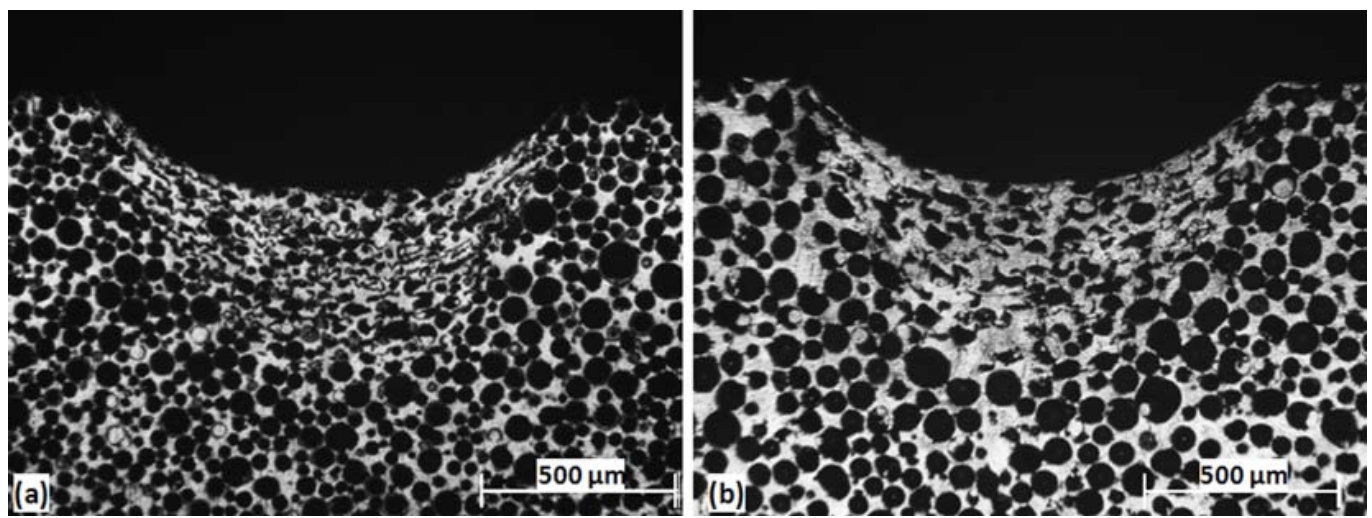

Fig. 9. The cross-sections of the imprints made by depth sensing hardness tests

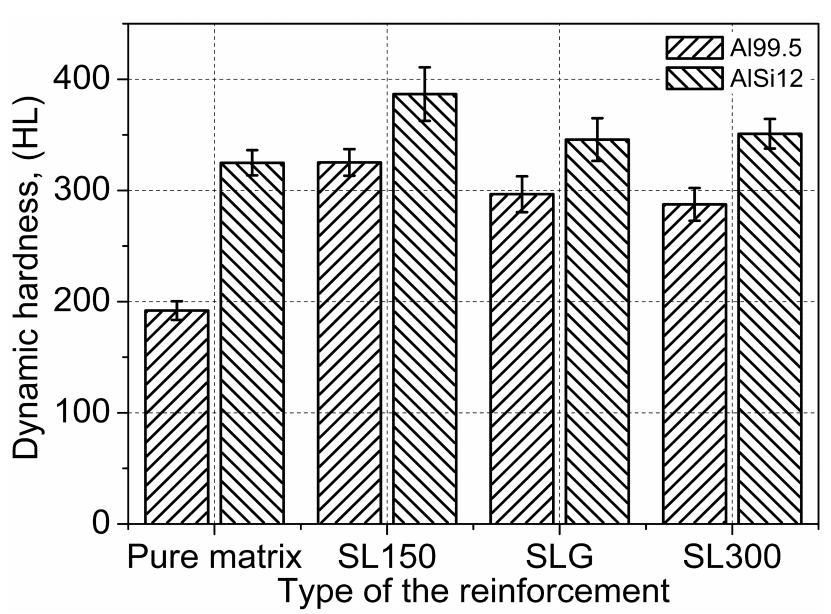

Fig. 10. The measured dynamic hardness values of the MMSFs

MMSFs originated from the ceramic microspheres. The highest dynamic hardness was produced by the MMSFs with SL150 microspheres. The indentations of the measurements were too small and too shallow for the preparation of their cross-sections as described in the previous paragraphs.

\section{Conclusions}

The hardness of A199.5 and AlSi12 matrix syntactic foams was higher and lower than their pure matrices respectively. The global hardness of the foams was almost the same regardless of the type of the matrix, therefore the global hardness of the MMSFs is structural property. The highest global hardness was ensured by the smallest microspheres (SL150) in the case of both matrices, because they ensure higher relative ceramic content, than the larger ones. Besides this the smaller microspheres have larger specific surface.

The depth sensing hardness tests showed great sensitivity to the deformation capability of the matrices and to the presence of a possible change reaction between the reinforcement and the matrices. The absorbed energy is the linear function of the slope of the loading.

The polished cross-sections of the indentations proved the excellent damage localizing capability of the MMSFs.

The dynamic hardness of the MMSFs was higher than that of the pure matrixes'. The matrix had low effect on the dynamic hardness; therefore it is a microsphere originated property. The highest dynamic hardness was measured in the case of the smallest microspheres (SL150).

\section{References}

1 Babcsán N, LeitImeier D, Banhart J, Metal foams-High temperature colloids Part I: Ex situ analysis of metal foams, Physicochem. Eng. Asp. 261 (2005), 123-130.

2 Babcsán N, Garcia Moreno F, Banhart J, Metal foams-High temperature colloids Part II: In situ analysis of metal foams, Physicochem. Eng. Asp. 309 (2007), 254-263.

3 Kallas DH, Chatten CK, Buoyancy materials for deep submergence, Ocean Eng. 4 (1969), 421-424, DOI 10.1016/0029-8018(69)90014-6.

4 Gupta N, Kishore, Woldesenbet E, Sankaran S, Studies on compressive failure features in syntactic foam material, J. Mater. Sci. 36 (2001), 4485 4491, DOI 10.1023/A:1017986820603.

5 Gupta N, Woldesenbet E, Kishore, Compressive fracture features of syntactic foams-microscopic examination, J. Mater. Sci. 37 (2002), 3199-3209, DOI 10.1023/A:1016166529841

6 Woldesenbet E, Gupta N, Jadhav A, Effects of density and strain rate on properties of syntactic foams, J. Mater. Sci. 40 (2005), 4009-4017, DOI 10.1007/s10853-005-1910-2

7 Fine $\mathbf{T}$, Sautereau $\mathbf{H}$, Sauvant-Moynot V, Innovative processing and mechanical properties of high temperature syntactic foams based on a thermoplastic/thermoset matrix, J. Mater. Sci. 38 (2003), 2709-2716, DOI 10.1023/A:1024403123013.

8 Daoud A, Synthesis and characterization of novel ZnAl22 syntactic foam composites via casting, Mater. Sci. Eng. A 488 (2007), 281-295, DOI 10.1016/j.msea.2007.11.020.

9 Ramachandra M, Radhakrishna K, Synthesis - microstructure - mechanical properties - wear and corrosion behaviour of an Al-Si (12\%) fly ash metal matrix composite., J. Mater. Sci. 40 (2005), 5989-5997, DOI 10.1007/s10853-005-1303-6

10 _ Effect of reinforcement of flyash on sliding wear, slurry erosive wear and corrosive behaviour of aluminium matrix composite, Wear 262 (2007), 1450-1462, DOI 10.1016/j.wear.2007.01.026.

11 Mondal D P, Đäs S, Ramakrishnan N, Uday Bashker K, Cenosphere filled aluminium syntactic foam made through stir-casting technique, Compos. Part A 40 (2009), 279-288, DOI 10.1016/j.compositesa.2008.12.006.

12 Rohatgi PK, Guo RQ, Iksan H, Borchelt EJ, Asthana R, Pressure infiltration technique for synthesis of aluminium - fly ash particulate composite Mater. Sci. Tech. A. 244 (1998), 22-30, DOI 10.1016/S0921-5093(97)00822-

13 Rohatgi PK, Kim JK, Gupta N, Alaraj S, Daoud A, Compressive char 
acteristics of A356/fly ash cenosphere composites synthesized by pressure infiltration technique, Composites Part A: Appl. Sci. and Manuf. 37 (2006), 430-437, DOI 10.1016/j.compositesa.2005.05.047.

14 Balch DK, O'Qwyer JG, Davis GR, Cady CM, Gray III. GT, Dunand DC, Plasticity and damage in aluminium syntactic foams deformed under dynamic and quasi-static conditions, Mater. Sci. Eng. A. 391 (2205), 408417, DOI 10.1016/j.msea.2004.09.012.

15 Blucher J T, Katsumata M, Method for producing composite material, December 18, 2001. Patent JP2001348633 (A).

16 Blucher J T, Discussion of a liquid metal pressure infiltration process to produce metal matrix composites, J. Mater. Proc. Tech. 30 (1992), 381-390.

17 Blucher JT, Németh Á, Production of aluminium alloy metal matrix composites with ceramic reinforcements, Proceedings of Second Conference on Mechanical Engineering Volume, 2000, pp. 634-638.

18 Bárczy T, Kaptay Gy, Modeling the infiltration of liquid metals into porous ceramics, Mater. Sci. Forum (2005), 297-302.

19 Trumble PK, Spontaneous infiltration of non-cylindrical porosity: closepacked spheres, Acta Mater. 46 (1998), 2363-2367, DOI 10.1016/S13596454(97)00392-3.

20 Erickson R, Syntactic metals: a survey of current technology, $5^{\text {th }}$ Aerospace Materials, Processes and Environmental Technology Conference, 2002.

21 Dou Z Y, Jiang L T, Wu G H, Zhang Q, Xiu Z Y, Chen G Q, High strain rate compression of cenosphere-pure aluminium syntactic foams, Scripta Mater. 57 (2007), 945-948.

22 Wu GH, Dou ZY, Sun DL, Jiang LT, Ding BS, He BF, Compression behaviours of cenosphere-pure aluminum syntactic foams, Scripta Mater. 56 (2007), 221-224, DOI 10.1016/j.scriptamat.2006.10.008.

23 Kiser M, He M Y, Zok F W, The mechanical response of ceramic microballoon reinforced aluminum matrix composites under compressive loading, Acta Mater. 47 (1999), 2685-2694.

24 Zhang L P, Zhao Y Y, Mechanical response of Al matrix syntactic foams produced by pressure infiltration casting, J. Compos. Mater. 41 (2007), 2105-2117.

25 Palmer RA, Gao K, Doan TM, Green L, Cavallaro G, Pressure infiltrated syntactic foams - Process development and mechanical properties, Mat. Sci. Eng. A. 464 (2007), 85-92, DOI 10.1016/j.msea.2007.01.116.

26 Rohatgi P K, Guo P K, Mechanism of abrasive wear of Al-Si hypoeutectic alloy containing 5 vol\% fly ash, Tribol. Let. 3 (1997), 339-347.

27 Mondal DP, Das J, Jha N, Dry sliding wear behaviour of aluminium syntactic foam, Mater. Design 30 (2008), 2563-2568.

28 Gubicza J, Juhász A, Lendvai J, A new method for hardness determination from depth sensing indentation tests, J. Mater. Res. 11 (1996), 29642967.

29 Gubicza J, Juhász A, Tasnádi P, Arató P, Vörös G, Determination of the hardness and elastic modulus from continuous Vickers indentation testing, J. Mater. Sci. 31 (1996), 3109-3114.

30 Gubicza J, Juhász A, Arató P, Szommer P, Tasnádi P, Vörös G, Elastic modulus determination from depth sensing indentation testing, J. Mater. Sci. Let. 15 (1996), 2141-2144.

31 Gubicza J, Determination of Young modulus from depth sensing Vickers indentation tests, Solid State Phenom. 5,6 (1997), 195-200.

32 Orbulov IN, Dobránszky J, Németh Á, Microstructural characterization of syntactic foams, J. Mater. Sci. 44 (2009), 4013-4019.

33 Metallic materials - Brinell hardness test. EN ISO 6506:2005. 